\title{
NEW CONVOLUTIONS ASSOCIATED WITH THE MELLIN TRANSFORM AND THEIR APPLICATIONS IN INTEGRAL EQUATIONS
}

\author{
L. P. Castro* , A. S. Silva and N. M. Tuan
}

\begin{abstract}
In this paper, we introduce two new convolutions associated with the Mellin transform which exhibit factorization properties upon the use of certain weight functions. This is applied to the solvability analysis of classes of integral equations. In particular, we present sufficient conditions for the solvability of an integral equation and a system of integral equations of convolution type.

Mathematics subject classification (2010): 44A35, 42A85, 44A15, 45E10, 45P05.

Keywords and phrases: Convolution, Mellin transform, convolution operator, factorization, integral equations of the convolution type.
\end{abstract}

\section{REFERENCES}

[1] G. Bogveradze, L. P. Castro, Toeplitz plus Hankel operators with infinite index, Integral Equations Operator Theory 62 (2008), no. 1, 43-63.

[2] P. L. Butzer, S. Jansche, A direct approach to the Mellin transform, J. Fourier Anal. 3 (1997), 325-376.

[3] L. P. Castro, R. Duduchava, F.-O. Speck, Finite interval convolution operators with transmission property, Integral Equations Operator Theory 52 (2005), no. 2, 165-179.

[4] L. P. Castro, R. C. Guerra, N. M. Tuan, On Wiener's Tauberian theorems and convolution for oscillatory integral operators, Turkish J. Math. 43 (2019), no. 3, 1124-1147.

[5] L. P. Castro, R. C. Guerra, N. M. Tuan, Convolution theorems related with the solvability of Wiener-Hopf plus Hankel integral equations and Shannon's sampling formula, Math. Slovaca 69 (2019), no. 5, 1149-1164.

[6] L. P. Castro, R. C. Guerra, N. M. Tuan, New convolutions weighted by Hermite functions and their applications, Math. Inequal. Appl. 22 (2019), no. 2, 719-745.

[7] L. P. Castro, L. T. Minh, N. M. TuAn, New convolutions for quadratic-phase Fourier integral operators and their applications, Mediterr. J. Math. 15 (2018), no. 13, 17 pp., https://doi.org/10.1007/s00009-017-1063-y.

[8] L. P. CAstro, A. S. Silva, Invertibility of matrix Wiener-Hopf plus Hankel operators with symbols producing a positive numerical range, Z. Anal. Anwend. 28 (2009), no. 1, 119-127.

[9] L. P. Castro, F.-O. Speck, F. S. TeIXeIRA, A direct approach to convolution type operators with symmetry, Math. Nachr. 269/270 (2004), 73-85.

[10] L. Debnath, D. Bhatta, Integral Transforms and Their Applications, 2nd ed., Chapman and Hall/CRC, New York, 2006.

[11] S. M. Khairnar, R. M. Pise, J. N. Salunkhe, Study of the mellin integral transform with applications in statistics and probability, Arch. Appl. Sci. Res. 4 (2012), no. 3, 1294-1310.

[12] Y. LuCHKO, Integral transforms of the Mellin convolution type and their generating operators, Integral Transforms Spec. Funct. 19 (2008), 809-851.

[13] O. I. MARICHEV, Handbook of Integral Transforms of Higher Transcendental Functions, Theory and Algorithmic Tables, Ellis Horwood Ltd., Chichester, 1983.

[14] W. SzPankows Ki, Average Case Analysis of Algorithms on Sequences, John Wiley \& Sons, Inc., New York, 2001.

[15] E. C. Titchmarsh, An Introduction to the Theory of Fourier Integrals, Clarendon Press, Oxford, 1937. 
Journal of Classical Analysis www.ele-math.com jcalele-math.com 